\title{
Maternal Deprivation Effect on the Infant's Neural Stress Markers Is Reversed by Tactile Stimulation and Feeding But Not by Suppressing Corticosterone
}

\author{
Helga J.J. van Oers, ${ }^{1,2}$ E. Ronald de Kloet, ${ }^{2}$ Tara Whelan, ${ }^{1}$ and Seymour Levine ${ }^{1}$ \\ ${ }^{1}$ Department of Psychology, University of Delaware, Newark, Delaware 19716-2577, and 2Division of Medical \\ Pharmacology, Leiden/Amsterdam Center for Drug Research, University of Leiden, 2300 RA Leiden, The Netherlands
}

\begin{abstract}
After $24 \mathrm{hr}$ of maternal deprivation, significant elevations in ACTH and the naturally occurring glucocorticoid corticosterone (CORT) are observed during the stress-hyporesponsive period. The deprived pups also showed in the paraventricular nucleus (PVN) a marked increase of stress-induced c-fos mRNA and a reduction of corticotropin-releasing hormone $(\mathrm{CRH})$ and glucocorticoid receptor (GR) mRNA; in hippocampal CA1, a reduction of the mineralocorticoid receptor (MR) and GR was observed. Here, we examined whether these changes are reversed by (1) preventing the elevations of CORT characteristic for the 11-d-old deprived pups by administering the synthetic glucocorticoid dexamethasone (DEX); or (2) reinstating some aspects of maternal behavior. The pups were either (1) left undisturbed, (2) stroked, or (3) stroked and episodically fed by cheek cannulation. At postnatal day 12, peripheral and neural stress markers were measured. Nondeprived animals served as controls.
\end{abstract}

Experiment 1 demonstrates that although CORT was kept low by DEX, the central effects on CORT receptors, $\mathrm{CRH}$, and c-fos mRNA were still present, except for MR in hippocampal CA1. Experiment 2 shows that stroking alone prevented the stress-induced rise in ACTH and c-fos mRNA and in the reduction in $\mathrm{CRH}$ and MR mRNA. In pups that were fed and stroked, CORT and GR mRNA resembled nondeprived controls. In conclusion, the changes in peripheral endocrine responses and in the brain cannot be attributed to the effect of elevated CORT concentrations, which are characteristic of the maternally deprived neonate. However, reinstating some components of the dams' nurturing behavior can reverse the effects evoked by maternal deprivation.

Key words: maternal deprivation; stress; brain; corticosterone; dexamethasone; corticosteroid receptors
During recent years, there has been a growing literature that indicates that the stress-hyporesponsive period (SHRP) is not absolute but rather is dependent on the stimulus used and on what component is measured (Witek-Janusek, 1988; Widmaier, 1989; Levine et al., 1994). Different stimuli seemed to elicit idiosyncratic patterns of ACTH release (Walker et al., 1991; Yi et al., 1994; Kent et al., 1996, 1997). However, the response of the adrenal during development seems markedly diminished, even in the presence of high ACTH (Rosenfeld et al., 1991, 1992).

It has also been documented that the suppression of the hypothalamic-pituitary-adrenal (HPA) axis during the SHRP is in part under maternal regulation (Stanton et al., 1988; Suchecki et al., 1993a, 1995). Pups that are exposed to $24 \mathrm{hr}$ of maternal deprivation exhibit a marked increase in "basal" level of the naturally occurring glucocorticoid corticosterone (CORT) and an increase in circulating levels of both ACTH and CORT in response to mild perturbations (Stanton et al., 1988; Suchecki et al., 1993a, 1995). Maternal deprivation also alters specific components of the neural systems that have been shown to be involved in the regulation of the peripheral stress hormones. Maternal deprivation at postnatal day $9(\mathrm{P} 9)$ and $\mathrm{P} 12$ results in a reduction of mineralocorticoid receptor (MR) mRNA in the CA1 region of

\footnotetext{
Received May 18, 1998; revised Sept. 14, 1998; accepted Sept. 16, 1998.

This work was supported by National Institutes of Mental Health Grant MH45006 (to S.L.) and NATO Collaboration Research Grant CRG 97.0477.

Correspondence should be addressed to Dr. S. Levine, Department of Psychology, University of Delaware, Newark, DE 19716-2577.

Copyright (C) 1998 Society for Neuroscience 0270-6474/98/1810171-09\$05.00/0
}

the hippocampus (Vazquez et al., 1996). Further, there is a significantly greater increase in $c$-fos mRNA in the paraventricular nucleus (PVN) of the hypothalamus and a paradoxical decrease in corticotropin-releasing hormone (CRH) mRNA after maternal deprivation (Smith et al., 1997).

Several studies have attempted to reverse the effects of maternal deprivation by experimentally replacing some of the elements of maternal behavior (Cirulli et al., 1991). Suchecki et al. (1993b) indicated that when pups received tactile stimulation the effects of maternal deprivation on the stress-induced rise in ACTH was completely reversed. Stroking the anogenital region was capable of normalizing the mechanisms that regulate the release of ACTH. Feeding in addition to stroking restored elevated CORT to basal levels and reduced the increased sensitivity of the adrenal to $\mathrm{ACTH}$, which appears to be one of the consequences of maternal deprivation. It was concluded that different maternal behaviors regulated different components of the developing HPA axis.

Pups deprived for $24 \mathrm{hr}$ are exposed to at least $16 \mathrm{hr}$ of elevated CORT, which could have caused the changes in brain. To test the hypothesis that the elevations of CORT induced the central changes after deprivation, we eliminated the rise in CORT by the administration of the synthetic glucocorticoid dexamethasone (DEX) at the beginning of the deprivation period. The results of these studies failed to support the hypothesis that CORT was responsible for the effects. Thus, a second experiment was conducted to determine whether the central effects of maternal deprivation could be reversed by reinstating maternal care. Al- 
most all of the effects of maternal deprivation were reversed by tactile stimulation of the anogenital region. The effects were completely reversed when the pups were stroked and fed.

\section{MATERIALS AND METHODS}

\section{Subjects}

The subjects were 12-d-old rat pups bred from Sprague Dawley females and Long-Evans males (Simonsen, Gilroy, CA). Hybrid offspring were used because they have a lower mortality rate than purebreds. Age was determined by checking for births every day at 9:00 A.M. and 5:00 P.M.; the date of birth was designated as P0. Litters were housed with their dams in transparent polycarbonate cages $(48.5 \times 25.6 \times 19.0 \mathrm{~cm}$; Nalgene) with a flooring of wood shavings and a grid top. Rat chow (Wayne Rodent Blox; Allied Mills, Chicago, IL) and tap water were provided ad libitum. The laboratory was maintained under constant temperature $\left(22^{\circ} \mathrm{C}\right)$ and lighting (12 hr light/dark cycle; lights on at 7:00 A.M.) conditions. On the day after birth (P1), litters were culled to eight pups (four males and four females) and placed in a clean cage. Cross-fostered pups were from litters born on the same day and were recorded for future reference during data analysis. From this moment on, the animals were not handled in any way, nor were their cages cleaned, until the time of deprivation or testing to minimize disruption of the mother-infant relationship. All experiments were performed in accordance with protocols approved by the Animal Care Committee of the University of Delaware.

\section{Deprivation procedure}

The mother was removed, and the litter remained in the home cage. The home cage, containing the litter, was placed on a heating pad (General Electric) set at $30-33^{\circ} \mathrm{C}$ in the deprivation room, adjacent to the main colony room. The deprivation room was kept under the same temperature and lighting conditions as the main colony room. Neither food nor water was available during the deprivation period. The nondeprived (NDEP) litters remained with their dams until time of testing.

\section{Sampling procedure}

Trunk blood from each pup was collected by decapitation a few seconds after disturbing the pups and placed in precooled plastic vials containing EDTA $(60 \mathrm{mg} / \mathrm{ml})$ kept on crushed ice. The samples were centrifuged for $20 \mathrm{~min}$ at $2000 \mathrm{rpm}$ at $2^{\circ} \mathrm{C}$, and the plasma was collected and placed in a marked precooled sample tube that was kept at $-20^{\circ} \mathrm{C}$ until radioimmunoassay procedure (RIA) for ACTH (INCSTAR kit) and CORT (ICN Biomedicals). The sensitivity of the ACTH and CORT assays was 15 $\mathrm{pg} / \mathrm{ml}$ and $0.125 \mu \mathrm{g} / \mathrm{dl}$, respectively.

At the time of blood sampling, brains were collected for measurement of mRNA expression of glucocorticoid receptor (GR), MR, and CRH. Brains were frozen immediately in a bucket containing 2-methylbutane kept at $-42^{\circ} \mathrm{C}$ on dry ice. The brains were stored at $-80^{\circ} \mathrm{C}$ until time of slicing and in situ hybridizations.

\section{Probes}

Different ${ }^{35}$ S-labeled cRNA antisense probes were used to hybridize with complementary brain tissue MR and GR mRNA. The antisense MR probes were transcribed from a 513 base pair (bp) rat brain cDNA fragment, which encodes for the last 30 amino acids at the $\mathrm{C}$ terminus of MR plus the adjacent highly specific 3' untranslated region (courtesy of R. M. Evans, The Salk Institute, La Jolla, CA). The antisense GR probe was transcribed from a $500 \mathrm{bp}$ cDNA fragment (courtesy of M. C. Bohn, University of Rochester, Rochester, NY), subcloned from a $2.8 \mathrm{~kb}$ fragment of the rat liver GR cDNA (courtesy of K. R. Yamamoto, University of California, San Francisco, CA), and encoded for the N-terminal region of the GR molecule.

For CRH mRNA measurements, a synthetic oligo-encoding rat $\mathrm{CRH}$ (48 nucleotides: 64-111) was prepared and $3^{\prime}$ end-labeled, using $\alpha-\left[{ }^{35} \mathrm{~S}\right]$ deoxyadenosine triphosphate (specific activity $>1000 \mathrm{Ci} / \mathrm{mmol}$; Amersham, Arlington Heights, IL) and terminal deoxynucleotidyltransferase (Boehringer Mannheim, Mannheim, Germany).

The $c$-fos probe consisted of an $860 \mathrm{bp}$ fragment containing the $3^{\prime}$ untranslated portion of the c-DNA (courtesy of T. Curran, St. Jude Children's Research Hospital, Memphis, TN).

\section{In situ hybridization}

Serial coronal sections were cut in a cryostat through the PVN $(12 \mu \mathrm{m})$ and hippocampus $(12 \mu \mathrm{m})$ according to the atlas of Paxinos and Watson
(1986). Brain sections were mounted on poly-L-lysine-coated slides and stored at $-80^{\circ} \mathrm{C}$ until hybridization. Tissue sections were incubated with $80 \mu \mathrm{l}$ of hybridization mix. The hybridization procedures described previously for adult brain tissue (Nicot, 1996) were used with minor modifications for the RNA probes in washing steps. Hybridization took place at $45^{\circ} \mathrm{C}$ overnight. The next day, sections were rinsed three times in $2 \times \mathrm{SSC}$ at room temperature (RT), two times during $15 \mathrm{~min}$ in $2 \times$ SSC $/ 50 \%$ formamide at $50^{\circ} \mathrm{C}$, and then a short dip at $37^{\circ} \mathrm{C}$, after which the sections were subjected to RNase A treatment $\left(20 \mu \mathrm{g} / \mathrm{ml}\right.$ at $37^{\circ} \mathrm{C}$ as described previously) to remove nonspecifically bound single-stranded probes. Then, the sections were washed three times during $15 \mathrm{~min}$ in $2 \times$ SSC $/ 50 \%$ formamide at $50^{\circ} \mathrm{C}$ and then in two final washes in $2 \times \mathrm{SSC}$ at RT. Dehydration was performed by grading ethanol series, after which the sections were air-dried and exposed for 7-14 d to Kodak X-OMAT AR film (Eastman Kodak, Rochester, NY) for semiquantification. The control study consisted of hybridization with the receptor-specific MR, $\mathrm{GR}$, and $c$-fos sense cDNA probes. In case the CRH probe was used, control sections were exposed to an RNase A digestion $(40 \mu \mathrm{g} / \mathrm{ml}$ for 30 $\min$ at $37^{\circ} \mathrm{C}$ ) before hybridization.

\section{Computer-assisted imaging analysis}

Optical density was quantified with an Olympus (Paes, The Netherlands), image analysis system equipped with a Cue CCD camera. The film background was subtracted after shading correction. Quantification occurred on the basis of a set of $\left[{ }^{14} \mathrm{C}\right]$ microscales, which are comparable with $\left[{ }^{35} \mathrm{~S}\right]$ scales (Amersham). Optical density values were converted into arbitrary units based on the respective standard curves. Analysis of MR and GR mRNA was performed on the dorsal hippocampus (minimum of 10 hippocampal lobi per rat). In the hypothalamic PVN (minimum of six sections with PVN per rat), between P1600 $\mu \mathrm{m}$ and P1200 $\mu \mathrm{m}$ posterior from bregma level GR, $c$-fos and CRH mRNA levels were measured (Paxinos and Watson, 1986).

\section{Data analysis}

Data were analyzed by ANOVA procedures (Winer, 1971), with the level of significance set at $p<0.05$. Initial ANOVA tests were performed separately for each age. Once sex had been determined not to be a significant variable, the data were collapsed across sexes. When appropriate, post hoc analyses for simple main and interaction effects were analyzed by Newman-Keuls or $t$ test procedures. All data are expressed as mean \pm SEM, and significance was accepted at $p<0.05$.

\section{Experimental designs}

\section{Experiment 1: effects of DEX on HPA axis function}

A 4 (conditions) $\times 5$ (treatments) $\times 2$ (gender) design was used. The conditions were as follows: deprived and nonstressed (DEP/NT); deprived and stressed (DEP/STRESS); nondeprived and nonstressed (NDEP/NT); and nondeprived and stressed (NDEP/STRESS). The treatments were as follows: nontreated (NT); DEX at onset of deprivation $(t=0 \mathrm{hr})(\mathrm{DEX} 0)$; DEX $12 \mathrm{hr}$ into deprivation period $(t=12 \mathrm{hr})$ (DEX12); DEX at $t=0$ and $12 \mathrm{hr}$ (DEX0/12); and saline at $t=0$ and 12 $\mathrm{hr}$ (SAL). The genders are as follows: male (M); and female (F). Treatment and gender were intralitter variables. DEX and SAL injections were administered at the onset of deprivation and/or $12 \mathrm{hr}$ into the deprivation time for DEP animals. NDEP animals received the injections at the equivalent time but were put back with the mothers until the time of testing.

Testing procedure. After $24 \mathrm{hr}$ of maternal deprivation or at the equivalent time for NDEP animals (P12), half of the pups were decapitated immediately, no stress (NS), which is within a few seconds after disturbing the pups. The remainder of the pups was injected with saline $(0.9 \%$, i.p.; volume, $0.1 \mathrm{ml} / 10 \mathrm{gm} \mathrm{BW}$ ) and placed back in their home cages on a heating pad set at $30-33^{\circ} \mathrm{C}$ for $30 \mathrm{~min}$, stress (S).

Injections. A dose of $100 \mu \mathrm{g} / \mathrm{kg}$ body weight (BW) was used for DEX injections. DEX was dissolved in a saline solution (0.9\%, i.p.; volume, 0.1 $\mathrm{ml} / 10 \mathrm{gm} \mathrm{BW})$.

\section{Experiment 2: effects of feeding and stroking on HPA axis function}

Feeding and stroking procedure. The cannulation procedure and feeding apparatus have been described previously in detail by Suchecki et al. (1993b). The pups that were stroked and fed during the time of deprivation were cannulated $24 \mathrm{hr}$ before testing (i.e., on P11 at the onset of deprivation). After cannulation, the pups' bladders were manually voided by gently stroking the anogenital area for $30-45 \mathrm{sec}$ or until urination 


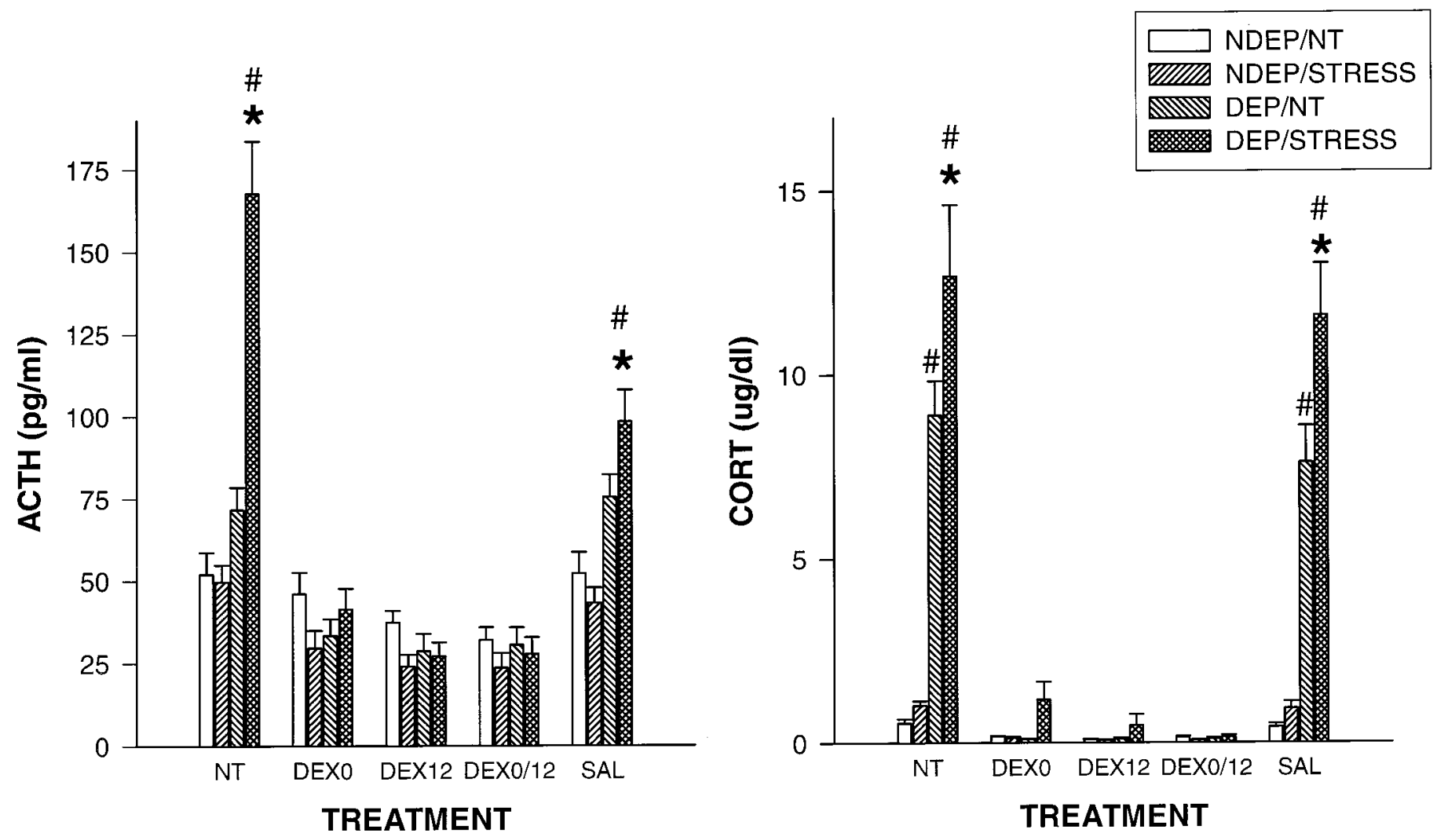

Figure 1. Plasma ACTH (picograms per milliliter) and CORT (micrograms per deciliter) levels in 12-d-old pups, both under basal condition (NT) and $30 \mathrm{~min}$ after a saline injection (STRESS). The DEP group had been deprived $24 \mathrm{hr}$ before testing $(n=10-12$ per group). NDEP animals served as controls. The DEX0 group had received a dexamethasone injection at the onset of deprivation, the DEX12 group received an injection $12 \mathrm{hr}$ into the deprivation period, and the DEX0/12 group received injections at both times (equivalent time for NDEP) of $100 \mu \mathrm{g} / \mathrm{kg} \mathrm{BW}$. SAL animals had received saline injections at the equivalent times. ${ }^{*} p<0.05$, significant from basal levels in DEP animals; \#p $<0.05$, significant from NDEP animals.

and/or defecation was observed. Another group of pups were only stroked at this time (STROK). All animals, except for the NDEP group, were placed in the deprivation chamber, and the fed pups were attached to the feeding apparatus. They were left undisturbed for the next $2 \mathrm{hr}$, and then the apparatus was turned on and all animals were left undisturbed until testing time ( $24 \mathrm{hr}$ after cannulation), except for two bladder-voiding sessions $\sim 7 \mathrm{hr}$ after cannulation and $2 \mathrm{hr}$ before testing in the DEP, fed and stroked (F \& S), and STROK groups. All animals were weighed at the beginning and end of the deprivation procedure.

Testing procedure. In this experiment, a 4 (conditions) $\times 2$ (treatments) $\times 2$ (gender) design was used. The conditions were as follows: nondeprived (NDEP); deprived (ISO); deprived and stroked (STROK); and deprived, stroked, and fed (F \& S). The treatments were as follows: nontreated (NT); and saline $30 \mathrm{~min}$ (STRESS). Gender was as follows: male $(\mathrm{M})$; and female $(\mathrm{F})$. NDEP controls were left undisturbed with their mothers until testing time (P12). The ISO, STROK, and F \& S litters were deprived for $24 \mathrm{hr}$ on P11, during which time they were either left undisturbed or manually stroked three times and stroked plus episodically fed. After $24 \mathrm{hr}$ of deprivation or at the equivalent time for NDEP animals, half of the pups were decapitated immediately (NT). The remainder of the pups was injected with saline (0.9\%, i.p.; volume, $0.1 \mathrm{ml} / 10 \mathrm{gm} \mathrm{BW}$ ) and placed back in their home cages on a heating pad set at $30-33^{\circ} \mathrm{C}$ for $30 \mathrm{~min}$ (STRESS).

\section{RESULTS}

\section{Experiment 1: effects of DEX on HPA axis function} $A C T H$

Main effects for condition, treatment, and an interaction were obtained by ANOVA $\left(F_{(3,193)}=31.51 ; p<0.001 ; F_{(4,193)}=62.77\right.$; $p<0.001 ; F_{(12,193)}=14.62 ; p<0.001$, respectively) (Fig. 1). Deprivation induced elevations of ACTH after stress in the NT and SAL groups $(p<0.01)$, as has been shown in multiple studies (Rosenfeld et al., 1992; Suchecki et al., 1993a). Administration of DEX prevented these stress-induced rises in ACTH. Injection at the onset of deprivation, $12 \mathrm{hr}$ into the deprivation period or at both time points, did show comparable low levels of basal and stress-induced ACTH.

\section{CORT}

The CORT data also showed main effects for condition $\left(F_{(3,166)}\right.$ $=79.77 ; p<0.001)$, treatment $\left(F_{(4,166)}=90.42 ; p<0.001\right)$, and an interaction $\left(F_{(12,166)}=25.27 ; p<0.001\right)$ (Fig. 1). Deprivationinduced elevations in basal and stress values were obtained from the control groups (NT and SAL) $(p<0.001)$. Administration of DEX also prevented these CORT rises, and again the different DEX treatments showed comparable low levels of basal and stress-induced CORT.

\section{Corticosteroid receptor $m R N A$ expression}

A downregulation in GR mRNA expression was observed in the hippocampal CA1 area of the DEP animals compared with NDEP/NT animals $(p<0.05)$. DEX injection was not able to prevent the downregulation in expression in these pups nor was DEX able to induce effects by itself. Deprivation and/or DEX injection did not cause changes in any of the other hippocampal regions (Fig. 2).

In the hippocampal CA1 area also, a downregulation in MR mRNA was observed after deprivation $(p<0.05)$. DEX injected 


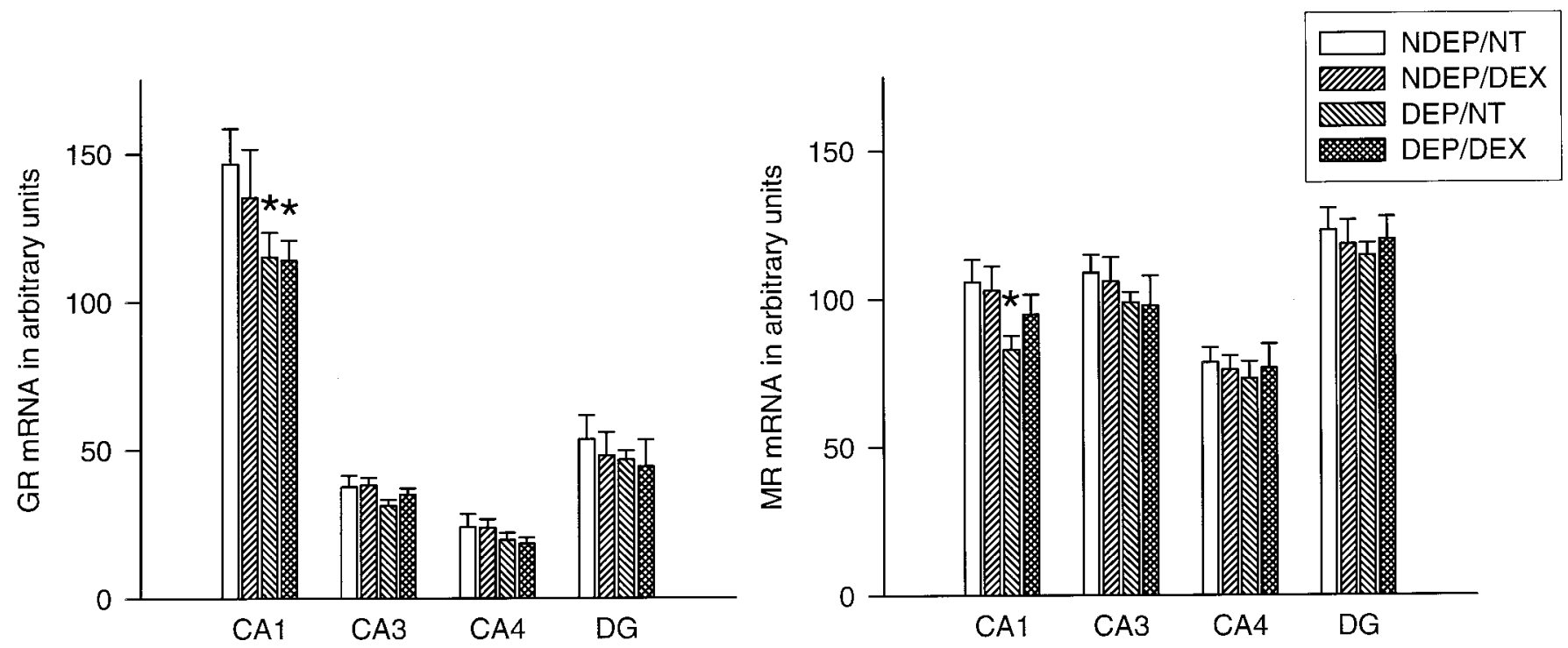

Figure 2. Basal MR and GR mRNA expression in different hippocampal subfields in 12-d-old animals. The DEP group had been deprived 24 hr before testing $(n=10-12$ per group). NDEP animals served as controls. The DEX animals had received a dexamethasone injection at the onset of deprivation (or equivalent time for NDEP) of $100 \mu \mathrm{g} / \mathrm{kg} \mathrm{BW}$. NT animals had received a saline injection instead of a DEX injection. ${ }^{*} p<0.05$, significant from NDEP counterparts.

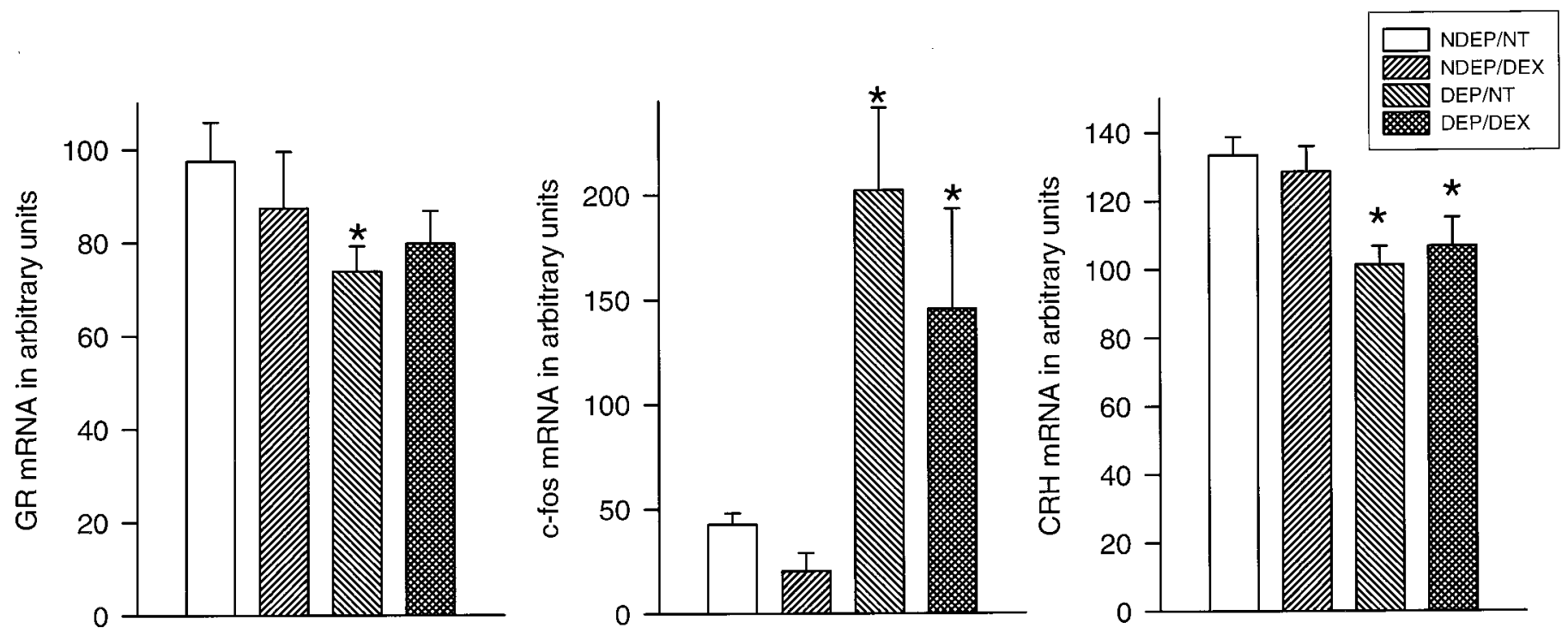

Figure 3. Basal CRH stress-induced (30 min after saline injection) $c$-fos and basal GR mRNA expression in the PVN of 12-d-old pups. The DEP group had been deprived $24 \mathrm{hr}$ before testing ( $n=10-12$ per group). NDEP animals served as controls. The DEX animals had received a dexamethasone injection at the onset of deprivation (or equivalent time for NDEP) of $100 \mu \mathrm{g} / \mathrm{kg} \mathrm{BW}$. NT animals had received a saline injection instead of a DEX injection. ${ }^{*} p<0.05$, significant from NDEP counterparts.

into the DEP animals resulted in a mRNA level that was not different from all the other groups. DEX injection was not able to induce any effects in the NDEP pups (Fig. 2).

The PVN revealed also a decrease in GR mRNA expression after deprivation $(p<0.05)$. This effect could be affected by the DEX administration in DEP animals; DEX administration resulted in a GR mRNA level that was not significantly different from any of the other groups $(p<0.05)$ (Fig. 3).

\section{CRH $m R N A$ expression in the PVN}

All DEP animals showed a decrease in CRH mRNA expression $(p<0.05)$. DEX injection at the onset of deprivation could not reverse this downregulation. DEX injection in NDEP animals was not able to induce any significant changes in message level compared with NT controls (Fig. 3).

\section{$C$-fos $m R N A$ expression in the PVN}

Despite the minimal endocrine response in NDEP rats, we observed a significant increase in $c$-fos mRNA levels in the PVN 30 min after the saline injection. However, stressing the DEP animals resulted in a large increase in $c$-fos mRNA levels, the magnitude of which was significantly greater than that seen in the NDEP stressed group $(p<0.01)$ (Fig. 3).

DEX injection at the onset of the deprivation period did not 


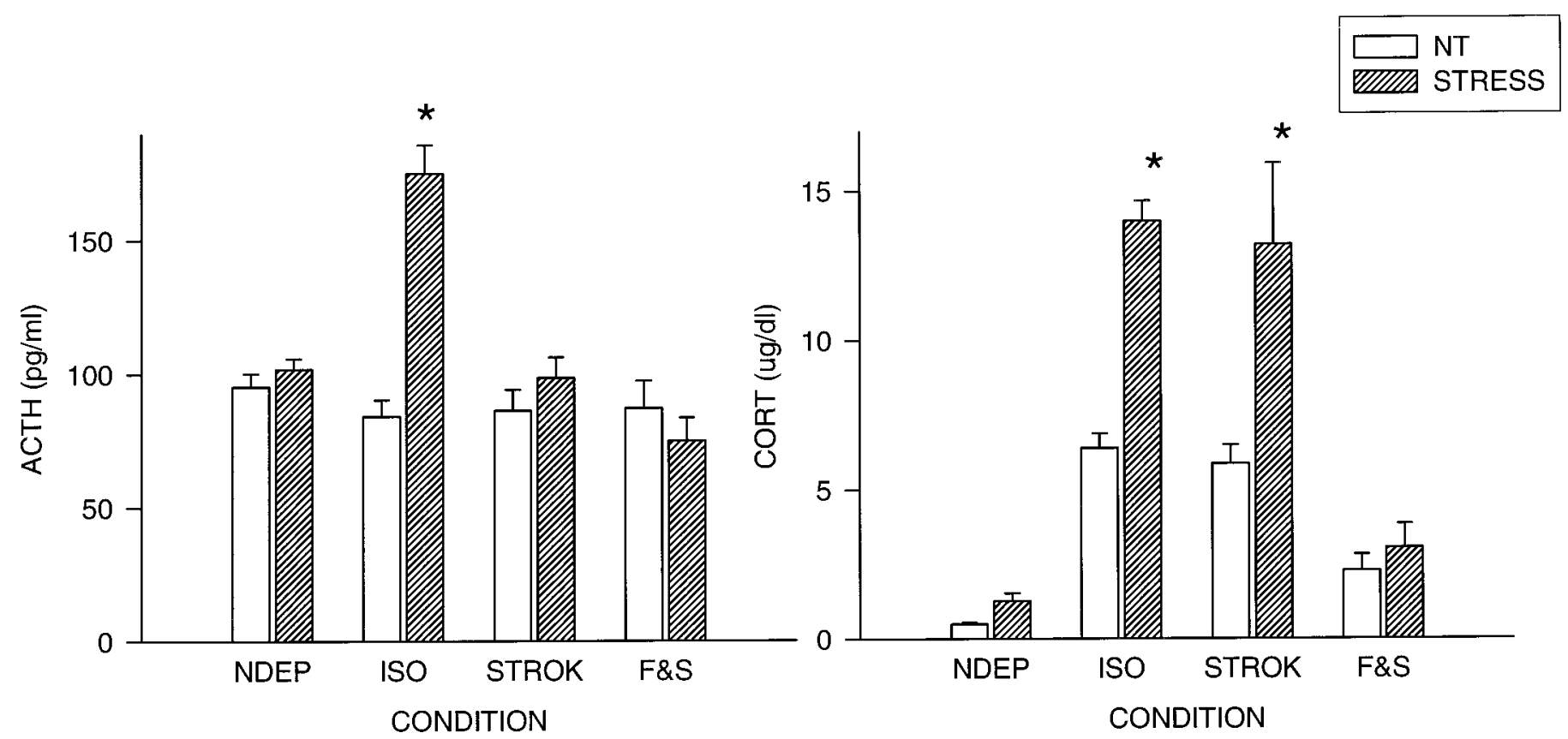

Figure 4. Plasma ACTH (picograms per milliliter) and CORT (micrograms per deciliter) levels in 12-d-old pups, both under basal condition (NT) and $30 \mathrm{~min}$ after a saline injection (STRESS). Litters were deprived for $24 \mathrm{hr}$ on P11, during which time they were either left undisturbed (ISO), stroked (STROK), or stroked and episodically fed (F \& S) $(n=10-12$ per group). NDEP animals served as controls. * $p<0.05$, significant from NDEP counterparts.

prevent the stress-induced rise in $c$-fos mRNA levels seen after deprivation. In addition, DEX did not induce any effects in NDEP animals.

\section{Experiment 2: effects of feeding and stroking on HPA axis function}

$A C T H$

ANOVA revealed main effects for condition $\left(F_{(3,96)}=13.86 ; p<\right.$ $0.001)$ and treatment $\left(F_{(1,96)}=20.81 ; p<0.001\right)$ (Fig. 4). In addition, an interaction was found between condition and treatment $\left(F_{(3,96)}=17.37 ; p<0.001\right)$. As previously reported in multiple studies, $24 \mathrm{hr}$ of maternal deprivation from P11-P12 results in a significant increase in ACTH response to a mild stimulus (saline injection) (ISO vs NDEP, $p<0.001$ ). Stroking the pups during the time of separation was sufficient to maintain low levels of ACTH. The F \& S group showed comparable levels with the STROK and the NDEP groups. The basal levels in the different condition groups did not differ.

\section{CORT}

The CORT levels also showed main effects for condition $\left(F_{(3,74)}\right.$ $=127.87 ; p<0.001)$ and treatment $\left(F_{(1,74)}=92.67 ; p<0.001\right)$, as well as an interaction $\left(F_{(3,74)}=20.75 ; p<0.001\right)$ (Fig. 4).

Also, the CORT levels showed a deprivation effect that has been reported previously: $24 \mathrm{hr}$ of deprivation results in elevations in basal and stress-induced CORT levels (NDEP vs ISO, $p<0.001$ ). To maintain low circulating levels of CORT, stroking alone of the deprived animals (ISO) was not sufficient. Feeding the pups during the time of deprivation prevented the rise in basal and stress-induced CORT levels (F \& S < ISO; $p<0.001$ ).

\section{Corticosteroid receptor $m R N A$ expression}

A downregulation in GR mRNA expression was observed in the PVN of all the DEP animals compared with NDEP controls $(p<$ $0.05)$. Stroking and feeding, although significantly higher than the
ISO and STROK groups, could not prevent completely the GR mRNA levels from decreasing (ISO $=\mathrm{STROK}<\mathrm{F} \& \mathrm{~S} ; p<$ 0.001) (Figs. 5, 6).

Although feeding and stroking could not completely reverse the decrease in GR mRNA level in the PVN, these manipulations could prevent the hippocampal decrease in GR mRNA expression in the CA1 area (ISO $<$ F \& S; $p<0.001$ ) (Fig. 5). Stroking alone was able to partially reverse this decrease in the CA1 area (ISO < STROK; $p<0.05)$, but the expression level was still significantly lower than in the $\mathrm{F} \& \mathrm{~S}$ and NDEP groups $(p<0.05)$. The other hippocampal subfields measured showed no effects.

MR mRNA expression showed a small but significant decrease after deprivation in the CA1 area of the hippocampus $(p<0.05)$ (Fig. 5). This decrease was not observed in any of the other regions measured. Stroked animals (and also the F \& S animals) no longer revealed differences from the NDEP rats.

\section{CRH $m R N A$ expression in the PVN}

The downregulation in CRH mRNA $(p<0.05)$ induced by $24 \mathrm{hr}$ of maternal deprivation was not observed in the animals that received either stroking alone or feeding and stroking during the time of deprivation (Figs. 6, 7).

\section{$C$-fos $m R N A$ expression in the PVN}

The marked increase in stress-induced $c$-fos mRNA levels after deprivation was completely prevented by stroking the animals during the time of deprivation. The stroked animals were not significantly different from the NDEP pups (Figs. 6, 8).

\section{DISCUSSION}

These studies once again showed that mother-reared pups showed little or no change in the endocrine parameters in response to the injection of isotonic saline, whereas pups displayed significant elevations of ACTH and CORT after $24 \mathrm{hr}$ of mater- 


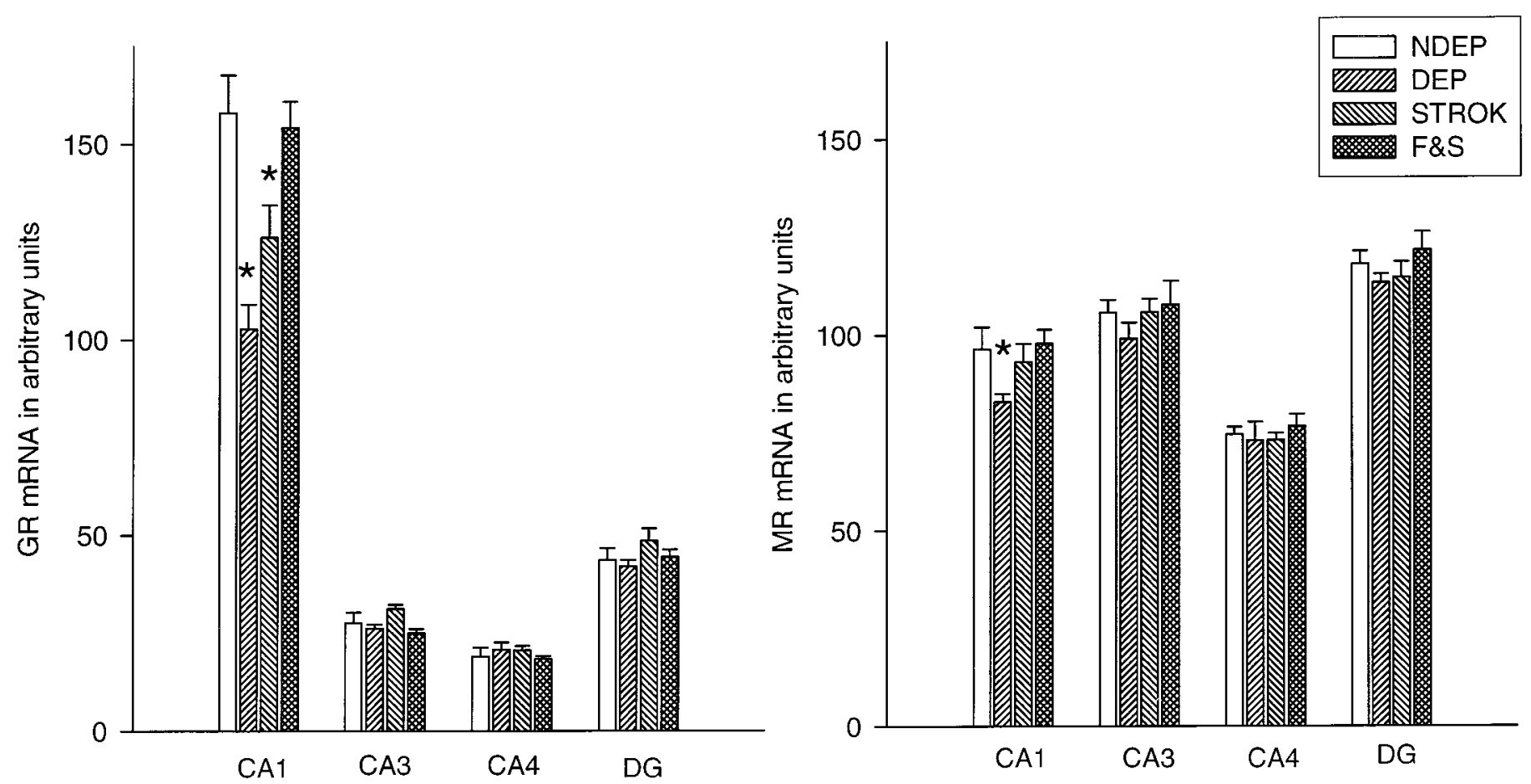

Figure 5. Basal MR and GR mRNA expression in different hippocampal subfields in 12-d-old animals. Litters were deprived for 24 hr on P11, during which time they were either left undisturbed (ISO), stroked (STROK), or stroked and episodically fed (F \& S) $(n=10-12$ per group). * $p<0.05$, significant from NDEP counterparts.

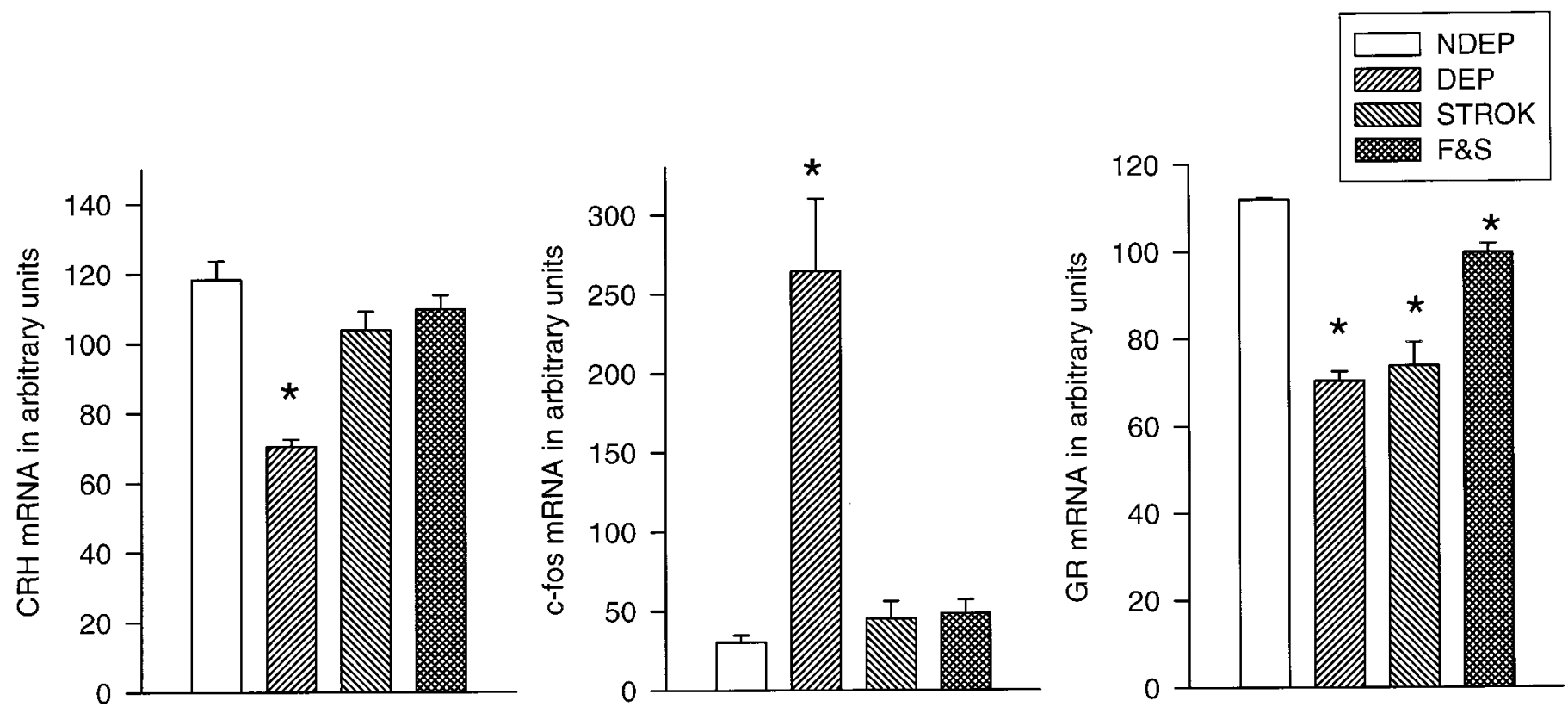

Figure 6. Basal CRH stress-induced (30 min after saline injection) c-fos and basal GR mRNA expression in the PVN of 12-d-old pups. Litters were deprived for $24 \mathrm{hr}$ on P11, during which time they were either left undisturbed (ISO), stroked (STROK), or stroked and episodically fed (F \& S) ( $n=$ $10-12$ per group). NDEP animals served as controls. ${ }^{*} p<0.05$, significant from NDEP counterparts.

nal deprivation after mild stress (Stanton et al., 1988; Rosenfeld et al., 1992; Suchecki et al., 1993a). The studies also showed that there are consistent changes in several components of the developing HPA axis. In the experiments reported here, the deprived pups exhibited the following changes: a marked stress-induced increase in $c$-fos mRNA, a reduction of CRH and GR mRNA in the PVN, and a reduction in GR and MR mRNA in the CA1 region of the hippocampus. These effects of maternal deprivation are very robust and have now been demonstrated in various studies (Vazquez et al., 1996; Smith et al., 1997). What is apparent from the current studies is that the changes that occur in the brain are not a function of the elevations of peripheral circulating hormones, but rather the disinhibition of the peripheral hormone response is more likely a function of the changes in the brain. 

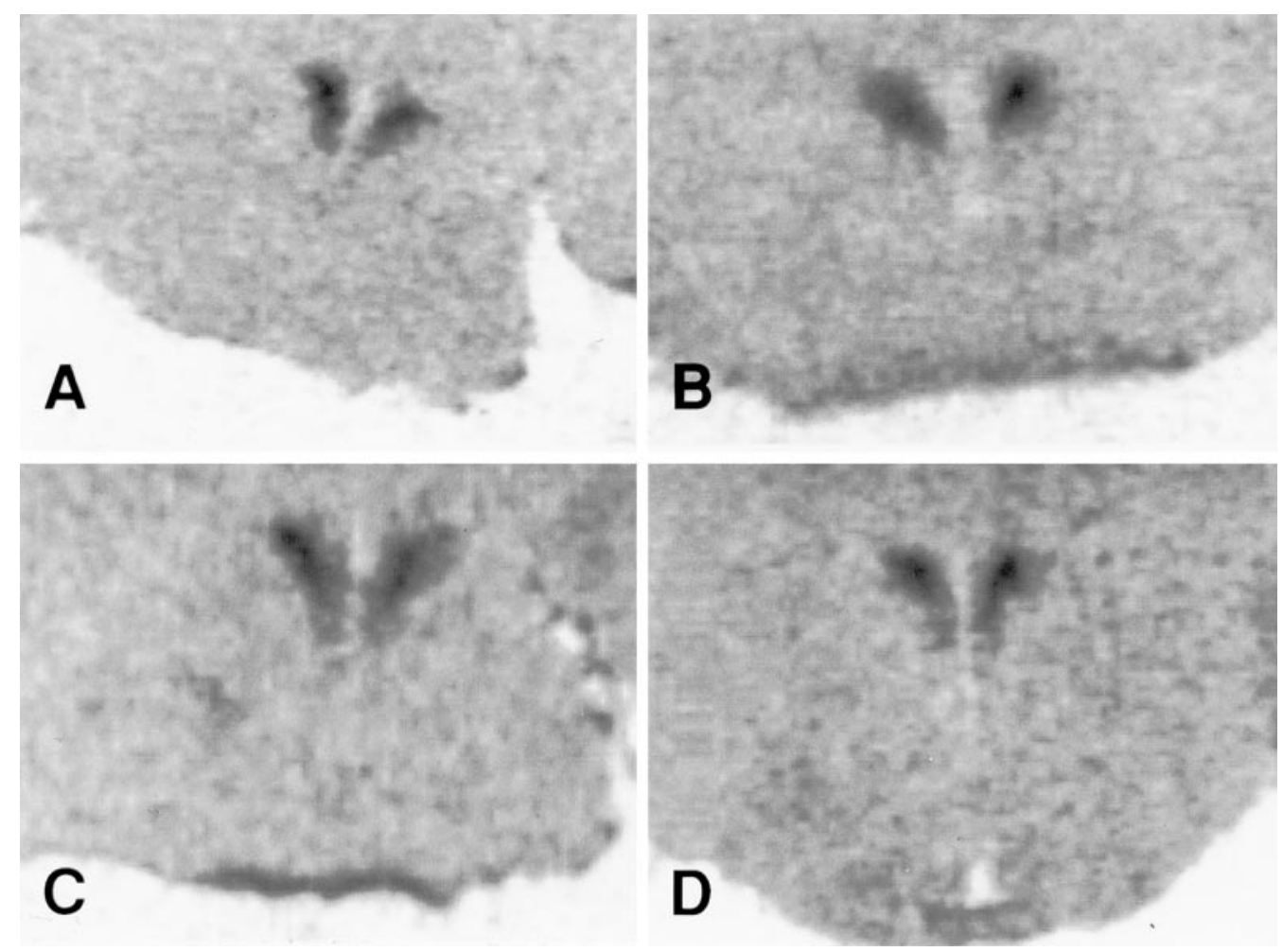

Figure 7. Photomicrographs of CRH mRNA expression in the PVN. $A$, NDEP. $B$, DEP. $C$, STROK. $D, \mathrm{~F} \& \mathrm{~S}$.
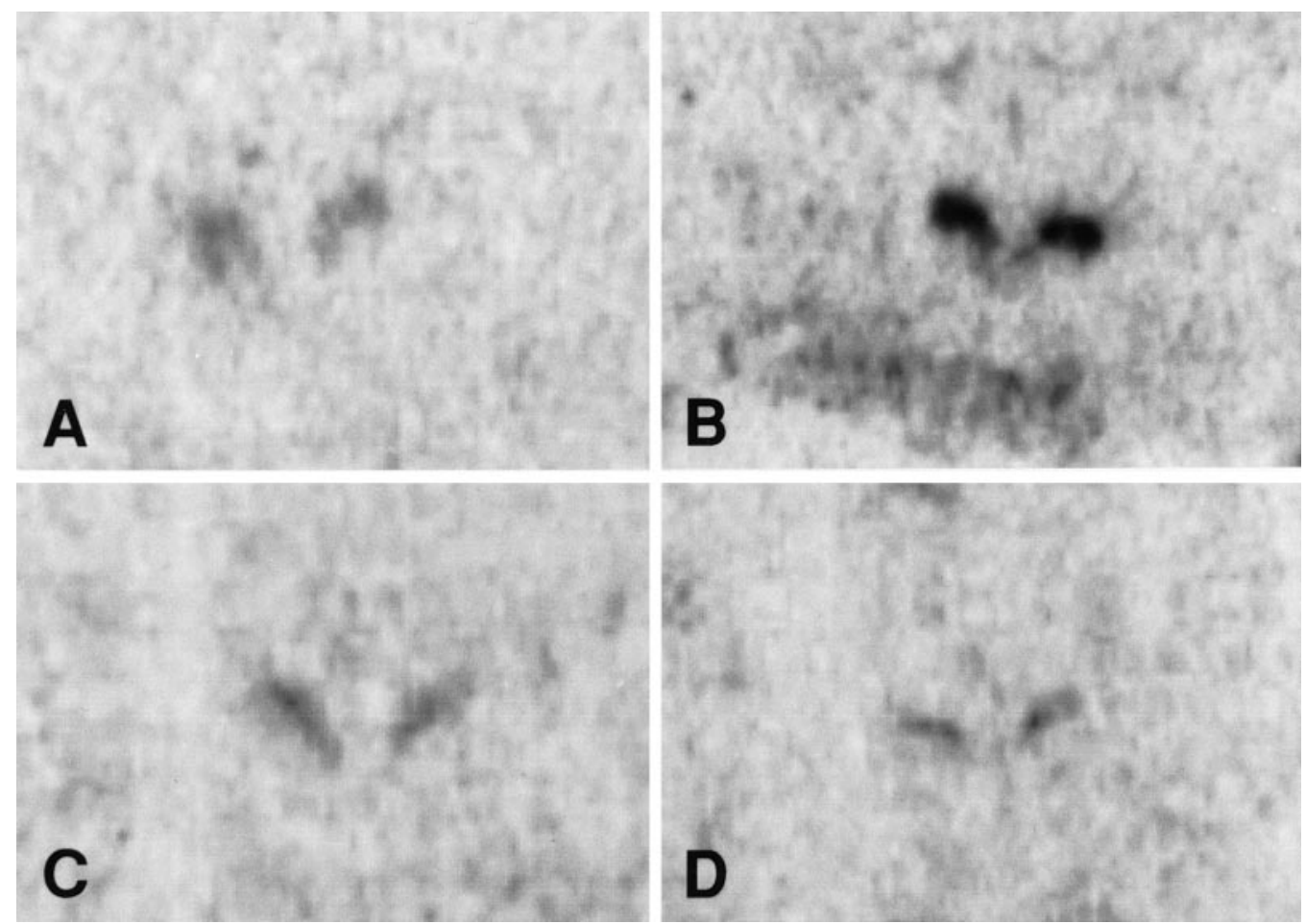

Figure 8. Photomicrographs of c-fos mRNA expression in the PVN. $A$, NDEP. $B$, DEP. $C$, STROK. $D$, F \& S.

The objective of the current studies was to determine whether the effects of maternal deprivation were reversible. Our original hypothesis was that the deprivation-induced changes in the brain were a consequence of the high circulating basal levels of CORT. It was thought that CORT would act on the developing CNS to transiently and permanently alter those structures that have been shown to be involved in the regulation of the HPA axis. Numerous studies have reported that exposure to high levels of CORT have detrimental effects on the developing brain (Bohn, 1984). To test the hypothesis, we administered a single injection of DEX at 
the onset of the deprivation period. This procedure effectively blocked the basal and stress elevations of CORT in deprived pups. However, in the absence of CORT elevations, all neural markers, except for MR, in hippocampal CA1 remained significantly different from mother-reared pups. Recently, Vazquez et al. (1996) also reported a reduction of MR mRNA after deprivation, which was attributed to the deprivation-induced elevations of CORT. It is therefore tempting to speculate that MR, which is normalized in DEX-treated deprived pups, is one aspect of the developing brain that is CORT-sensitive. However, the results of the stroking and feeding experiment failed to provide evidence that elevations of CORT are solely responsible for the downregulation of MR mRNA. Thus, the hypothesis was not supported that the mechanism responsible for the brain changes seen in deprived pups was solely dependent on the persistent elevation of CORT.

The purpose of DEX administration was to block the secretion of endogenous CORT in deprived pups. There were no indications that DEX as used in these experiments had any effects on gene expression in any of the transcripts measured in nondeprived pups. There is some debate as to whether DEX crosses the blood-brain barrier. It has been reported that DEX poorly penetrates the blood-brain barrier because of the P-glycoproteins in the blood-brain barrier (Schinkel et al., 1996; De Kloet, 1997; Meijer et al., 1998). It is likely that the feedback action of CORT was at the level of the pituitary and that the brain of both the nondeprived and deprived pups were minimally exposed to DEX.

Manipulations, which were intended to mimic some of the critical aspects of maternal behavior, were capable of reversing most of the effects of maternal deprivation. The deprived pups that were stroked and fed during the deprivation period closely resembled nondeprived pups. This was the case for the endocrine responses, as well as for those changes observed in brain. The stroked and fed pups failed to show elevations in basal and stress-induced ACTH and CORT and further failed to elicit a c-fos response in PVN. CRH and GR mRNA were also normalized. Stroking the anogenital region to stimulate urination and defecation reversed the stress-induced ACTH response, although the basal and stress-related elevations of CORT were similar to totally deprived neonates. The $c$-fos and CRH changes that occur with deprivation were reversed, as well as the downregulation of MR mRNA. However, the deprivation-induced downregulation of GR mRNA in the hippocampus and PVN were still present in stroked pups.

It has been proposed that there are two distinct components of maternal behavior that regulate different elements of the HPA axis in the neonate: (1) feeding, which reduces the sensitivity of the adrenal to ACTH; and (2) stimulation of the anogenital region, which is involved in the inhibition of ACTH (Suchecki et al., 1993b). It appears that a similar dual regulatory process also occurs in the brain. Thus, stroking alone is sufficient in eliminating the effects of maternal deprivation on CRH and $c$-fos that occur in the PVN and hippocampal MR mRNA, whereas the effects on GR mRNA in both hippocampus and PVN require the addition of feeding. It is difficult to determine to what extent feeding and stroking interact, because anogenital stimulation is required to stimulate eliminative functions during this period of development and is an integral component of the nurturing activities of the dam. What is clear is that when both components of the dam's behavior are reinstated the pup is more like a mother-reared animal and is stress-hyporesponsive. It should be noted that the degree of stimulation provided to the neonate in these studies is indeed minimal: a total of $135 \mathrm{sec}$ divided into three $45 \mathrm{sec}$ bouts of anogenital stroking. Yet this is sufficient to reverse many of the effects of maternal deprivation. That somatosensory experiences influence some aspects of cortical development is discussed and demonstrated in reviews by Greenough (1990) and Meszenich (1990). The process by which maternal tactile stimulation can alter cortical and subcortical development is unexplored. We have investigated only a few, albeit key parameters, of the numerous elements that make up the neuroendocrine regulatory mechanisms of the HPA system. It is difficult to determine at this time how many other aspects of the developing brain are dependent on maternally initiated tactile stimulation.

In many ways, the deprived neonate is similar to the adult that is stress-responsive. ACTH and CORT are elevated, and there is a marked increase in c-fos mRNA in the PVN (Smith et al., 1997), which has been used as a marker of neuronal activity and has been validated as a marker of increased neuronal activity after exposure to a variety of stressful events. However, a significant difference is that in the mature animal ACTH elevations are generally preceded by the release of CRH from the nerve terminals of the median eminence, which act on the pituitary corticotrophs. This is followed by a compensatory increase in CRH mRNA in the PVN (Lightman and Harbuz, 1993; Yi et al., 1994). In the deprived pup, a downregulation in CRH mRNA seems to be characteristic after $24 \mathrm{hr}$ of maternal deprivation. This suggests that perhaps earlier during the deprivation period CRH had been released and that the neonate does not have the capacity to compensate either by decreasing $\mathrm{CRH}$ mRNA transcription or increasing $\mathrm{CRH}$ degradation. In general, changes in CRH mRNA have been difficult to elicit in the mother-reared neonates. In one instance, 9-d-old pups did show an increase in $\mathrm{CRH}$ transcription in response to severe cold (Yi et al., 1994). However, it has also been reported by this same group that CRH mRNA is decreased in response to a chronic stress and disturbed mother-infant interactions and more recently that $\mathrm{CRH}$ mRNA is reduced after $10 \mathrm{~d}$ of brief disturbances of mother-infant interactions (handling) (Eghbal-Ahmadi et al., 1997).

In conclusion, we find that $24 \mathrm{hr}$ of maternal deprivation is associated with changes in the endocrine and neuroendocrine response to stress in the 12 -d-old rat pup. The changes in the peripheral endocrine responses and in the brain cannot be attributed to the effects of elevated CORT levels, which are characteristic of maternally deprived neonates. However, reinstating some of the components of the dam's nurturing behavior can reverse the effects of maternal deprivation. Stroking and feeding the pup can reverse almost all of the effects created by maternal deprivation. Stroking alone also reverses some of the effects of maternal deprivation. Thus, the increased ACTH response and the increased $c$-fos and decreased CRH mRNA are returned to normal, whereas the elevation of CORT levels and the downregulation of the GR mRNA are not affected by tactile stimulation.

\section{REFERENCES}

Bohn MC (1984) Glucocorticoid induced teratologies of the nervous system. In: Neurobehavioral teratology (Yanai J, ed.), pp 365-387. Amsterdam: Elsevier Science.

Cirulli F, Gottlieb SL, Rosenfeld P, Levine S (1991) Maternal factors regulate stress responsiveness in the neonatal rat. Psychobiology 20:143-152.

De Kloet ER (1997) Why dexamethasone poorly penetrates in brain. Stress 2:13-21.

Eghbal-Ahmadi M, Avishai-Eliner CG, Hatalski AG, Snodgrass SR, Baram TZ (1997) The corticotropin releasing factor receptor CRF2 is 
down-regulated in maternally deprived neonatal rats. 23rd Annual Meeting of the Society for Neuroscience 23:990.

Greenough W (1990) Brain storage of information from cutaneous and other modulations in development and adulthood. In: Touch: the foundation of experience (Katheryn ED, Barnard E, Berry Brazelton T, eds), pp 97-128. Madison, CT: International Universities.

Kent S, Kernahan SD, Levine S (1996) Effects of excitatory amino acids on the hypothalamic-pituitary-adrenal axis of the neonatal rat. Dev Brain Res 94:1-13.

Kent S, Tom C, Levine S (1997) Pituitary-adrenal, feeding, and immune responses to interleukin- $1 \beta$ in the neonatal rat: interaction with maternal deprivation. Stress 1:213-231.

Levine S, Berkenbosch F, Suchecki D, Tilders FJH (1994) Pituitaryadrenal and interleukin-6 responses to recombinant interleukin- 1 in neonatal rats. Psychoneuroendocrinology 19:143-153.

Lightman SL, Harbuz MS (1993) Expression of corticotropin-releasing factor mRNA in response to stress. In: Corticotropin releasing factor, pp 173-198. Chicester, UK: Wiley.

Meijer OC, De Lange ECM, Breimer DD, De Boer AG, De Kloet ER (1998) Penetration of dexamethasone into brain glucocorticoid targets is enhanced in mdr1a P-glycoprotein knock-out mice. Endocrinology 139:1789-1793.

Meszenich M (1990) Development and maintenance of corticalsomatosensory representation: functional "maps" and neuroanatomical repertoires. In: Touch: the foundation of experience (Katheryn ED, Barnard E, Berry Brazelton T, eds) pp 47-72. Madison, CT:International Universities.

Nicot A, Rostène W, Bérod A (1995) Differential neurotensin receptor mRNA expression in dopaminergic cell groups of the rat di- and mesencephalon. J Neurosci Res 40:667-674.

Paxinos G, Watson C (1986) The rat brain in stereotaxic coordinates. San Diego: Harcourt Brace Jovanovich.

Rosenfeld P, Gutierrez YA, Martin AM, Mallett HA, Alleva E, Levine S (1991) Maternal regulation of the adrenocortical response in preweanling rats. Physiol Behav 50:661-671.

Rosenfeld P, Suchecki S, Levine S (1992) Multifactorial regulation of the hypothalamic-pituitary-adrenal axis during development. Neurosci Biobehav Rev 16:553-568.

Schinkel AH, Wagenaar E, Van Deemster L, Mol CAAM, Borst P (1996)
Absence of mdr1a-glycoprotein in mice affects tissue distribution and pharmacokinetics of dexamethasone, digoxine and cyclosporin A. J Clin Invest 96:1698-1705.

Smith MA, Kim S-Y, Van Oers HJJ, Levine S (1997) Maternal deprivation and stress induce immediate early genes in the infant rat brain. Endocrinology 138:4622-4628.

Stanton ME, Gutierrez YR, Levine S (1988) Maternal deprivation potentiates pituitary-adrenal stress responses in infant rats. Behav Neurosci 102:692-700.

Suchecki D, Mozaffarian D, Gross G, Rosenfeld P, Levine S (1993a) Effects of maternal deprivation on the ACTH stress response in the infant rat. Neuroendocrinology 57:204-212.

Suchecki D, Rosenfeld P, Levine S (1993b) Maternal regulation of the hypothalamic-pituitary-adrenal axis in the infant rat: the roles of feeding and stroking. Dev Brain Res 75:185-192.

Suchecki D, Nelson DY, Van Oers H, Levine S (1995) Activation and inhibition of the hypothalamic-pituitary-adrenal axis of the neonatal rat: effects of maternal deprivation. Psychoneuroendocrinology 20:169-182.

Vazquez DM, Van Oers HJJ, Levine S, Akil H (1996) Regulation of glucocorticoid and mineralocorticoid receptor mRNAs in the hippocampus of the maternally deprived infant rat. Brain Res 731:79-90.

Walker CD, Scribner K, Cascio CS, Dallman MF (1991) The pituitaryadrenocortical system of neonatal rat is responsive to stress throughout development in a time-dependent and stressor-specific fashion. Endocrinology 128:1385-1395.

Widmaier EP (1989) Development in rats of the brain-pituitaryadrenal response to hypoglycemia in vivo and in vitro. Am J Physiol 257:E757-E763.

Winer BJ (1971) Analysis of covariance. In: Statistical principles in experimental design (Garmezy N, Solomon RL, Jones LV, Stevenson HW, eds) pp 752-812. New York: McGraw-Hill.

Witek-Janusek L (1988) Pituitary-adrenal response to bacterial endotoxin in developing rats. Am J Physiol 225:E525-E530.

Yi S-J, Baram TZ (1994) Corticotropin-releasing hormone mediates the response to cold stress in the neonatal rat without compensatory enhancement of the peptide's gene expression. Endocrinology 6:23642368. 